\title{
EFEITOS DE GIBERELINAS NA MORFOLOGIA PRODUTIVIDADE DO FEIJOEIRO (Phaseolus vulgaris L. cv. 'Carioca')
}

\author{
Paulo R. C. Castro \\ Eliana C. Bergemann
}

\section{RESUMO}

\begin{abstract}
Verificou-se os efeitos de giberelinas, quando aplicadas sob a forma de pulverização das plântulas, na morfologia, florescimento e produtividade do feijoeiro cultivar 'Carioca'; em condiçoes de casâ de vegetação.

Estudou-se as concentraçరes de 0, 50,500 e $1000 \mathrm{ppm}$ do regulador de crescimento; sendo que os tratamentos com 500 e $50 \mathrm{ppm}$ do produto revelaram-se mais efetivos. As aplicacóes de giberelinas promoveram aumentos significativos no comprimento da haste princlpal e dos meritalos.

Verificou-se um ligeiro incremento no número de meritalos e no número de folhas nas plantas tratadas com o regulador de crescimento. Os tratamentos com giberelinas promoveram maior florescimento; não observou-se porém, diferencas significativas entre a produtividade das plantas tratadas, com relação ao controle.
\end{abstract}

\section{INTRODUÇAO}

As giberelinas foram descobertas quando foi estudada a razão do crescimento excessivo de plantas de arroz no Japão, devido a ocorrência de doença fúngica causada por Gibberella fujikuroi (Saw.) Wr. (KUROSAWA, 1926).

YABUTA (1935) conseguiu cristalizar o composto de extrato do fungo pela primeira vez, dando-lhe a denominação de giberelina; sendo que CROSS (1954) estabeleceu as estruturas moleculares das giberelinas. Esses compostos começaram então a serem isolados de fungos e de plantas superiores (CROSS et al., 1961). Giberelina é um composto isoprenóide formado de diterpenos, os quais constituem metabólitos bem conhecidos de Angiospermas. Acredita-se que em plantas superiores, os precursores imediatos de giberelina sejam caureno e esteviol, variando provavelmente com a espécie (WEST et al., 1969; RUDDAT, 1969).

\footnotetext{
* Entregue para publicação em 26/3/1973.

** Departamento de Botanica. E.S.A. "Luiz de Queiroz" - U.S.P.

*** Engenheiro-Agrônomo. C. A. T. I. - SECRETARIA DA AGRICULTURA.
} 
Em cereais, as giberelinas induzem a produção da alfa-amilase, a qual hidrolisa o amido de reserva do endosperma, sendo que, na produção da amilase, a giberelina age provavelmente através da desrepressão dos genes codificados para a enzima (GALSTON \& DAVIES, 1970). 0 mais evidente ef eito resultante da aplicação de giberelinas, em grande número de plantas, é o aumento no comprimento do caule. A causa primária da elongação do caule e um aumento no comprimento das células, anterior a um incremento no número de células (SALISBURY \& ROSS, 1969).

KURAISHI \& HASHIMOTO( 1957) verificaram que a giberelina causa promoção do crescimento foliar e elongação da haste de ervilha, sendo que o produto se transloca de forma acropétala. CHIN \& LOCKHART (1965) estudando a translocação de giberelina aplicada em plântulas de feijoeiro (Phaseolus vulgaris L. cv. 'Pinto'), observaram evidente crescimento da haste quando o produto era aplicado na primeira folha trifoliada ou na extremidade apical; mas essa elongação era menor quando a giberelina foi aplicada nas folhas primárias. 0 tempo necessário para uma quantidade suficiente de giberelina translocar-se da folha, para aumentar o crescimento da haste, foi inferior a 1 hora. 0 crescimento máximo foi verificado quando a folha tratada era deixada na planta 3 ou mais horas. 0 movimento da giberelina aplicada na planta está relacionado com o transporte de carboidratos no vegetal.

MOH \& ALAN (1967) verificaram que aplicações semanais de ácido giberélico de 1 a 32 ppm são capazes de converter um mutante anão de feijoeiro em um fenótipo normal. Sendo este mutante anão controlado por um gene recessivo simples, acredita-se que a ação deste gene para nanismo é obstruir completa ou parcialmente a biossíntese para a produção de uma substância do tipo do ácido giberélico, necessária para o crescimento normal.

LESHEM \& STEINER (1968) verificaram que o florescimento da couve-flor teve sua maior precocidade quando combinou-se tratamento frio com a aplicação de giberelina. $O$ tratamento reduziu em média o número de meritalos e aumentou o comprimento dos mesmos. Embora a elongação da haste não esteja correlacionada com a aceleração do florescimento, os autores sugerem que a antecipação do mesmo pela giberelina não envolve necessariamente a elongação do pedúnculo. LESHEM \& KOLLER (1966) observaram que a aplicação de ácido giberélico no estágio de diferenciação floral do morangueiro, promove a elongação do pedúnculo; verificaram ainda aumento do número de estolões, assim como no comprimento individual dos mesmos. Aplicação de giberelina após a iniciação do botão floral, mas antes da emergência do pedúnculo, afetou a distribuição da colheita. As plantas tratadas com ácido giberélico produziram mais que o controle na primeira metade da frutificação, mas na segunda metade ocorreu o inverso, sendo que a colheita total não foi afetada.

WITTWER \& BUKOVAC (1957) verificaram que a aplicação de giberelina em feijoeiro, nas condições de campo, não causou aumento na produtividade e houve necessidade de estaqueamento nas plantas tratadas com o regulador de crescimento. ALVIM (1960) observou que o ácido giberélico incrementa a 
taxa de assimilação aparente, a taxa de crescimento relativo, o peso seco da haste, a área foliar e a altura de plantas de feijoeiro. Verificou-se ainda redução no peso seco das raízes ; sendo que o peso seco das folhas não foi alterado significativamente.

O objetivo deste trabalho foi verificar o ef eito de giberelinas, aplicadas em pulverização foliar, no desenvolvimento morfológico da parte aérea, florescimento e produtividade do feijoeiro cultivar 'Carioca', sob condições de casa de vegetação.

\section{MATERIAIS E MÉTODOS}

Neste experimento utilizou-se o feijoeiro, Phaseolus vulgaris L. cv. 'Carioca'. $O$ ensaio desenvolveu-se em casa de vegetação, tendo-se realizado a semeadura (1/3/1972) diretamente em vasos de cerâmica com capacidade para 5 litros, contendo solo com adubo químico (N-P-K).

A emergência das plantas verificou-se entre os dias 5 e $7 / 3 / 1972$, sendo que no decorrer do ciclo das mesmas realizaram-se os tratos culturais normais para a cultura do feijoeiro.

Aplicou-se as giberelinas em 13 de março de 1972, nas concentrações de $0,50,500$ e $1000 \mathrm{ppm}$, por pulverização da solução aquosa do produto. Pulverizou-se toda a parte aérea, principalmente as folhas, até ficarem bem molhadas, sendo que o tratamento testemunha recebeu tão somente água.

0 delineamento experimental utilizado foi de blocos ao acaso com 6 repetições, tendo uma planta por repetição. Neste estudo das variabilidades morfológicas do feijoeiro, sob diferentes níveis do regulador de crescimento, determinou-se os seguintes parâmetros:

$$
\begin{aligned}
& \text { a - comprimento da haste principal }(\mathrm{cm}) \\
& \text { b - comprimento dos meritalos }(\mathrm{cm}) \\
& \text { c - número de meritalos } \\
& \text { d - comprimento do limbo foliar }(\mathrm{cm}) \\
& \text { e - número de folhas }
\end{aligned}
$$

Efetuou-se as medidas e contagens duas vezes por semana, à partir de 18/3/1972.

Quanto ao florescimento, realizou-se leituras diárias às 8 horas, para obter-se o número de flores por planta, tendo-se iniciado em 4/4/1972 (34 dias após o plantio) e finalizado em 22/4/1972 (52 dias após o plantio). No que se refere à produtividade, verificou-se os seguintes parâmetros:

$$
\begin{aligned}
& \mathrm{f} \text { - peso das vagens por planta }(\mathrm{g}) \\
& \mathrm{g} \text { - peso dos grãos por planta }(\mathrm{g}) \\
& \mathbf{h} \text { - número de grãos por planta }
\end{aligned}
$$

Efetuou-se a análise estatística para os parâmetros referentes à morfologia e produtividade; sendo que para o florescimento utilizou-se a colocação gráfica. 


\section{RESULTADOS E DISCUSSAO}

\section{Comprimento da haste principal}

Observou-se um crescimento médio na haste principal do feijoeiro da ordem de $16,2 \mathrm{~cm} /$ dia no tratamento com giberelinas $500 \mathrm{ppm}$, relativamente a um crescimento de $4,8 \mathrm{~cm} /$ dia na testemunha, entre os dias 18 e 22/3/1972. Esta diferença foi decrescente com relação ao decorrer do ciclo do feijoeiro (quadro 1).

Durante a produtividade biológica da planta, giberelinas na concentração de $500 \mathrm{ppm}$ mostraram-se mais favoráveis para o crescimento da haste principal, seguida por giberelinas na concentração de $50 \mathrm{ppm}$. 0 regulador de crescimento na dosagem de $1000 \mathrm{ppm}$ mostrou efeito menos pronunciado, mas superior ao tratamento controle.

Com referência à análise estatística, verificou-se maiores diferenças entre os tratamentos, no que se refere ao comprimento da haste principal, dos 9 aos 12 dias após a aplicação do produto. Essas diferenças ainda são notadas (F significativo ao nível de $5 \%$ ) na primeira quinzena do mês segtuinte. $O$ coeficiente de variação encontra-se entre baixo e médio.

\section{Comprimento dos meritalos}

Pelo quadro 2 pode-se concluir que os tratamentos com giberelinas nas concentrações de 500 e $50 \mathrm{ppm}$ mostraram-se mais favoráveis ao crescimento dos meritalos; sendo que o tratamento com 1000 ppm teve efeito menos pronunciado, mas superior à testemunha.

Com referência à análise estatística, pode-se notar diferenças significativas entre os tratamentos, ao nível de $5 \%$ para os dias $18 / 3,29 / 3$ e $1 / 4$; e ao nível de $1 \%$ de probabilidade para os dias 22 e $25 / 3$. A maior diferença no comprimento dos meritalos ocorreu entre os dias 18 e $22 / 3$, que são as datas mais próximas à de aplicação das giberelinas (13/3). A partir de $5 / 4$ não se observou diferenças significativas entre os tratamentos.

\section{Número de meriłalos}

No que se refere ao número de meritalos, verifica-se pelo quadro 3 a ocorrência de poucas diferenças entre os tratamentos.

Essas diferenças somente se revelaram significativas ao nível de $5 \% \mathrm{em}$ 8 e 15/4. Nota-se que a aplicação de giberelinas parece mostrar-se ligeiramente favorável no aumento do número de meritalos.

\section{Comprimento do limbo foliar}

Verificou-se uma ligeira superioridade na elongação dos limbos foliares nos tratamentos com giberelinas na concentração de $50 \mathrm{ppm}$ e testemunha, com relação aos tratamentos com giberelinas a 500 e 1000 ppm, no decorrer do ciclo das plantas (quadro 4). 
A diminuição no crescimento das folhas com aplicações do regulador de crescimento nas dosagens de 500 e 1000 ppm em relação ao controle, parece ter ocorrido devido à sensibilidade foliar às mais elevadas concentrações de giberelinas aplicadas, resultando num ef eito negativo ao desenvolvimento. Pelo teste $\mathrm{F}$ verificou-se apenas em $8 / 4$ diferença significativa, ao nível de $1 \%$ de probabilidade, entre os tratamentos.

\section{Número de folhas}

Pelo quadro 5 pode-se concluir que as diferenças foram mínimas, no número de folhas, em resposta à aplicação das giberelinas. A análise estatística revela que não houve diferença significativa entre os tratamentos.

\section{Número de flores}

Observando-se os dados relativos ao florescimento diário, pode-se notar que pela aplicação das giberelinas, houve diferenças no florescimento relativas ao nível de concentração do produto (figura 1). 0 tratamento com giberelinas que apresentou maior florescimento foi na concentração de $500 \mathrm{ppm}$, vindo em seguida o tratamento com $50 \mathrm{ppm}$ do regulador de crescimento. Com a aplicação de $1000 \mathrm{ppm}$, notou-se uma diminuição no florescimento, em relação às demais plantas tratadas com giberelinas; sendo, no entanto, ainda superior ao tratamento controle.

Através da figura 1 nota-se que houve o aparecimento de maior número de flores entre os 38 e 42 dias após o plantio, sendo que de 42 a 47 dias após plantio houve uma diminuição no florescimento, observando-se novamente um pequeno acréscimo entre 47 e 50 dias após o plantio. 0 momento de maior florescimento ocorreu 40 dias após o plantio, e o de florescimento mínimo, 47 dias após o plantio, para a maioria dos tratamentos, durante o período considerado (34 a 52 dias após o plantio).

\section{Produtividade}

Para o estudo da produtividade determinou-se o peso das vagens por planta, peso dos grãos por planta e número de grãos por planta.

Pelo quadro 6 pode-se concluir que houve uma tendência de aumento na produtividade para as três concentrações de giberelinas utilizadas, com relação à testemunha. Nota-se que as plantas tratadas com o produto nas concentrações de 500 e 1000 ppm apresentaram resultados mais promissores; sendo que a concentração de $50 \mathrm{ppm}$ e o tratamento controle mostraram resultados inferiores.

A análise estatística revelou que não houve diferenças significativas entre os tratamentos, indicando assim que as giberelinas não afetam o peso das vagens, peso dos grãos e número de grãos, por planta, não provocando deste modo, alterações significativas na produtividade. 


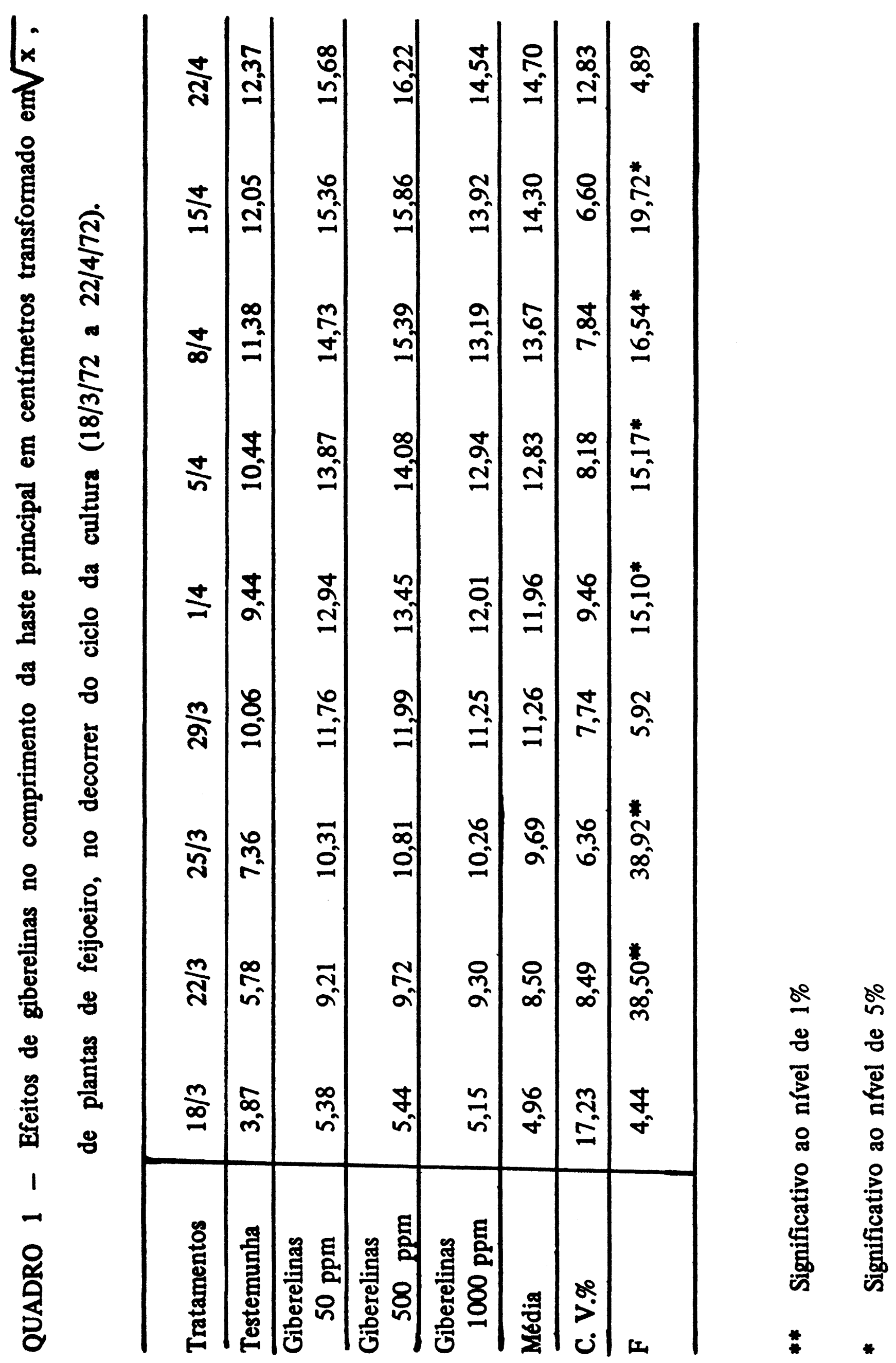




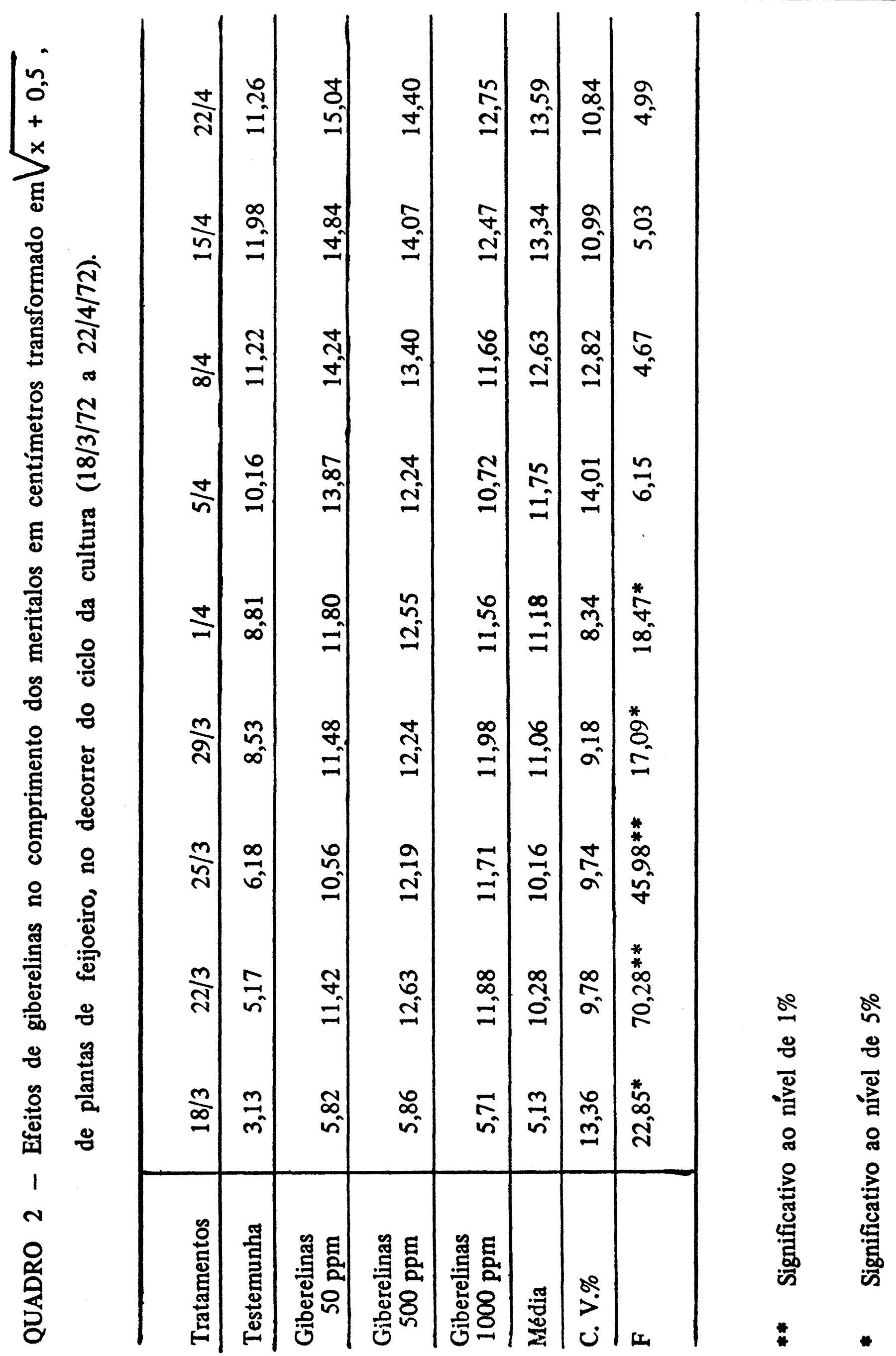




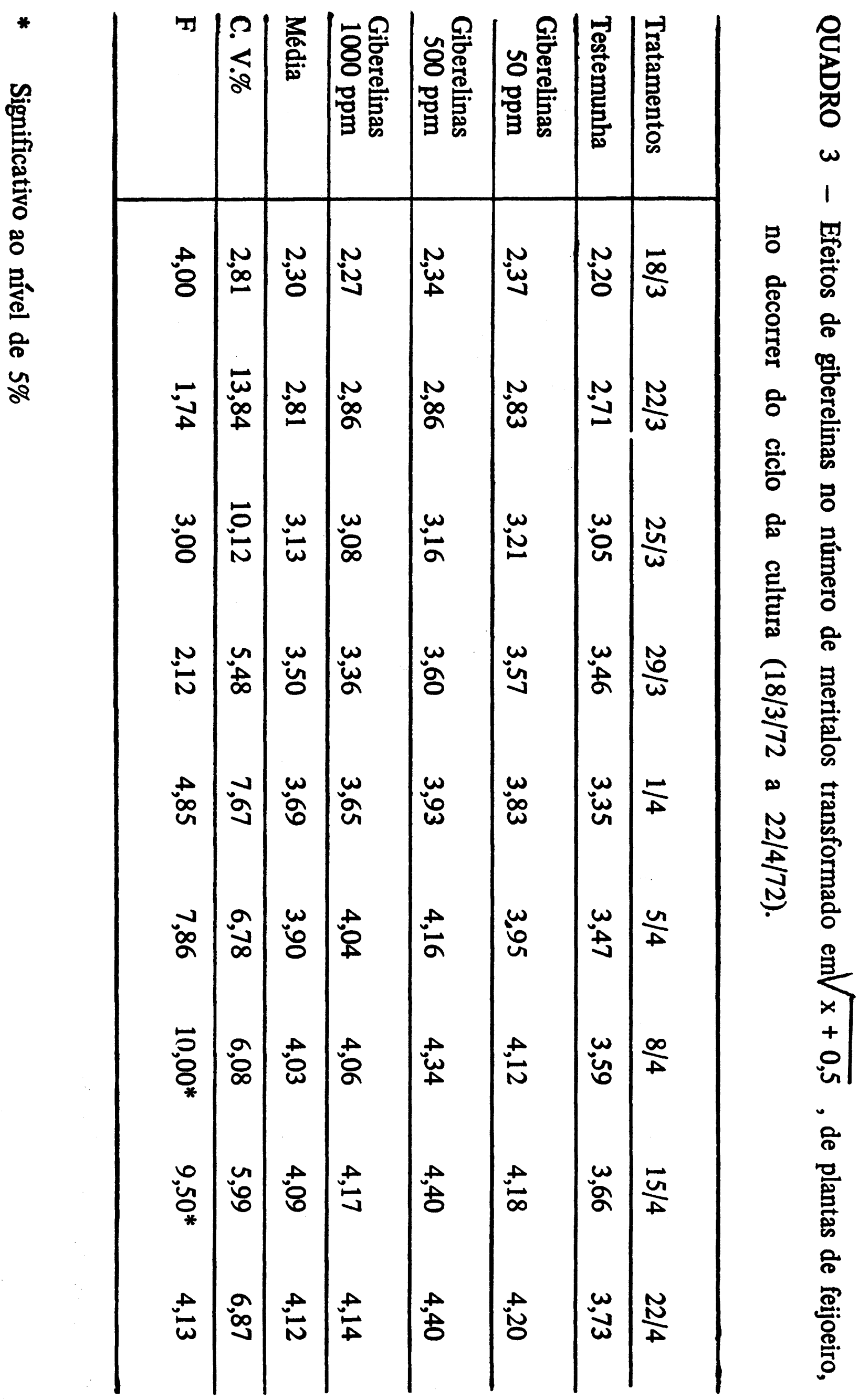




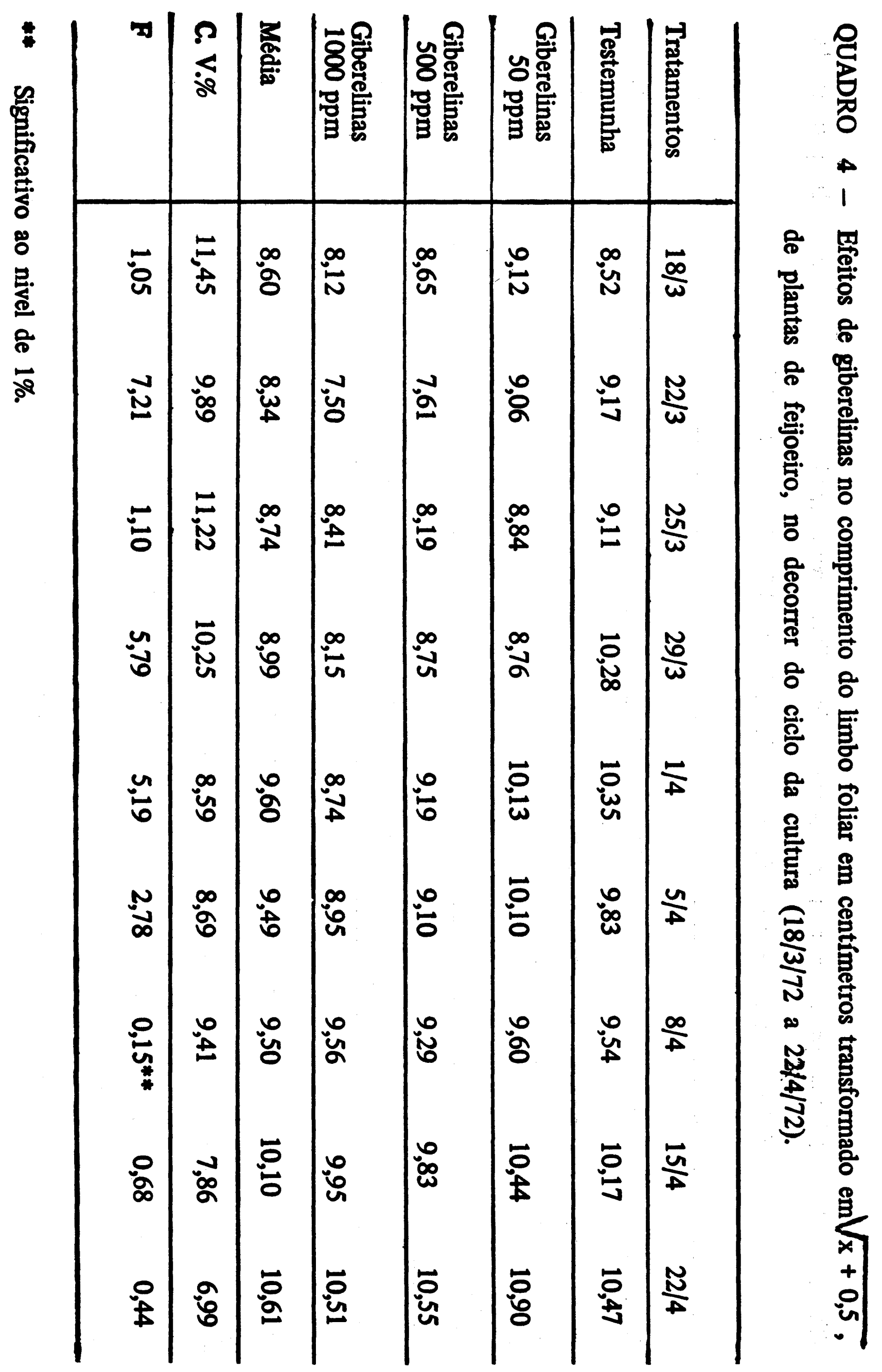




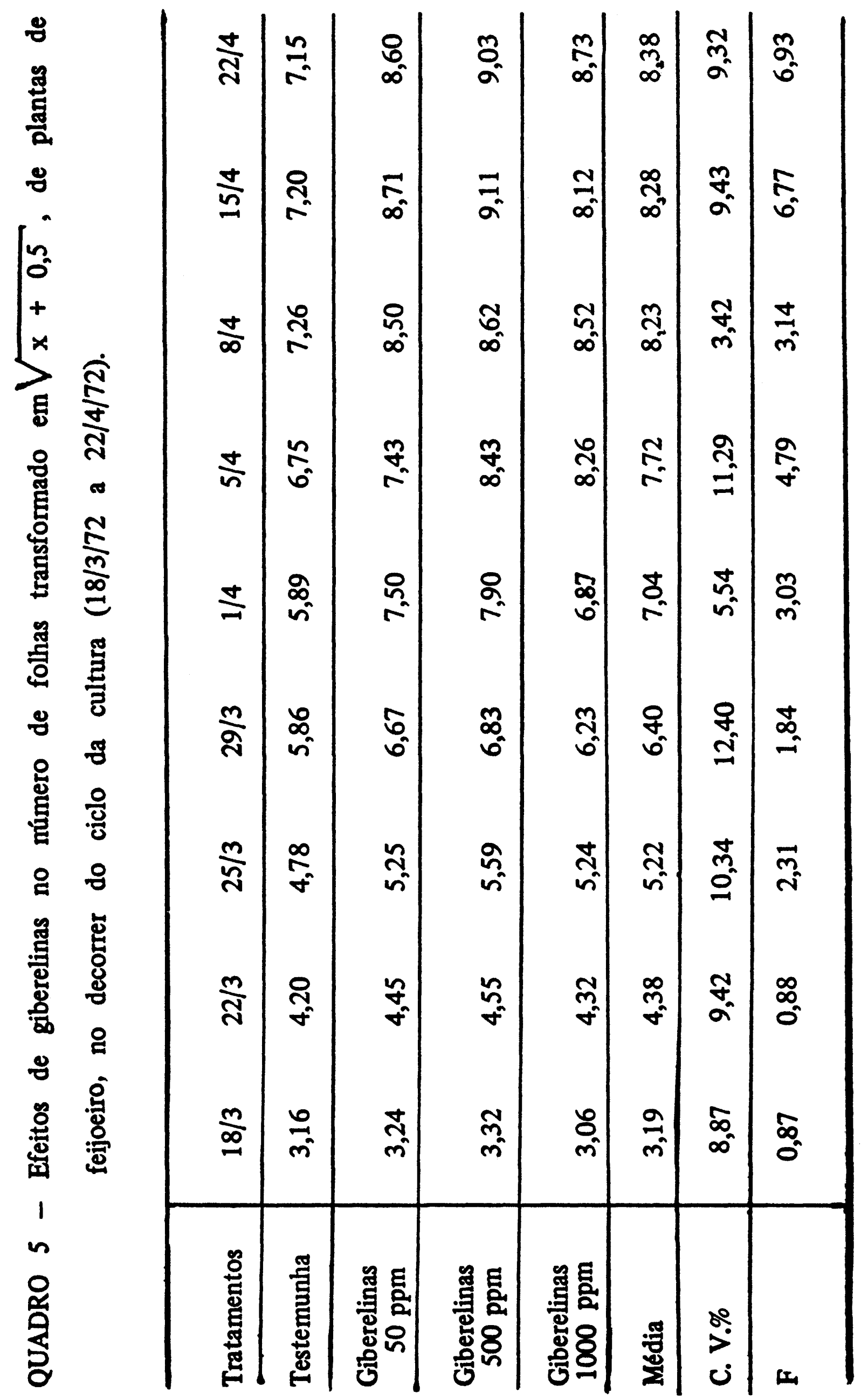


FIgURA 1 - Efeitos de giberelinas no número médio de flores por dia, por planta de feijoeiro. no decorrer do período de florescimento ( 34 a 52 dias após o plantio).

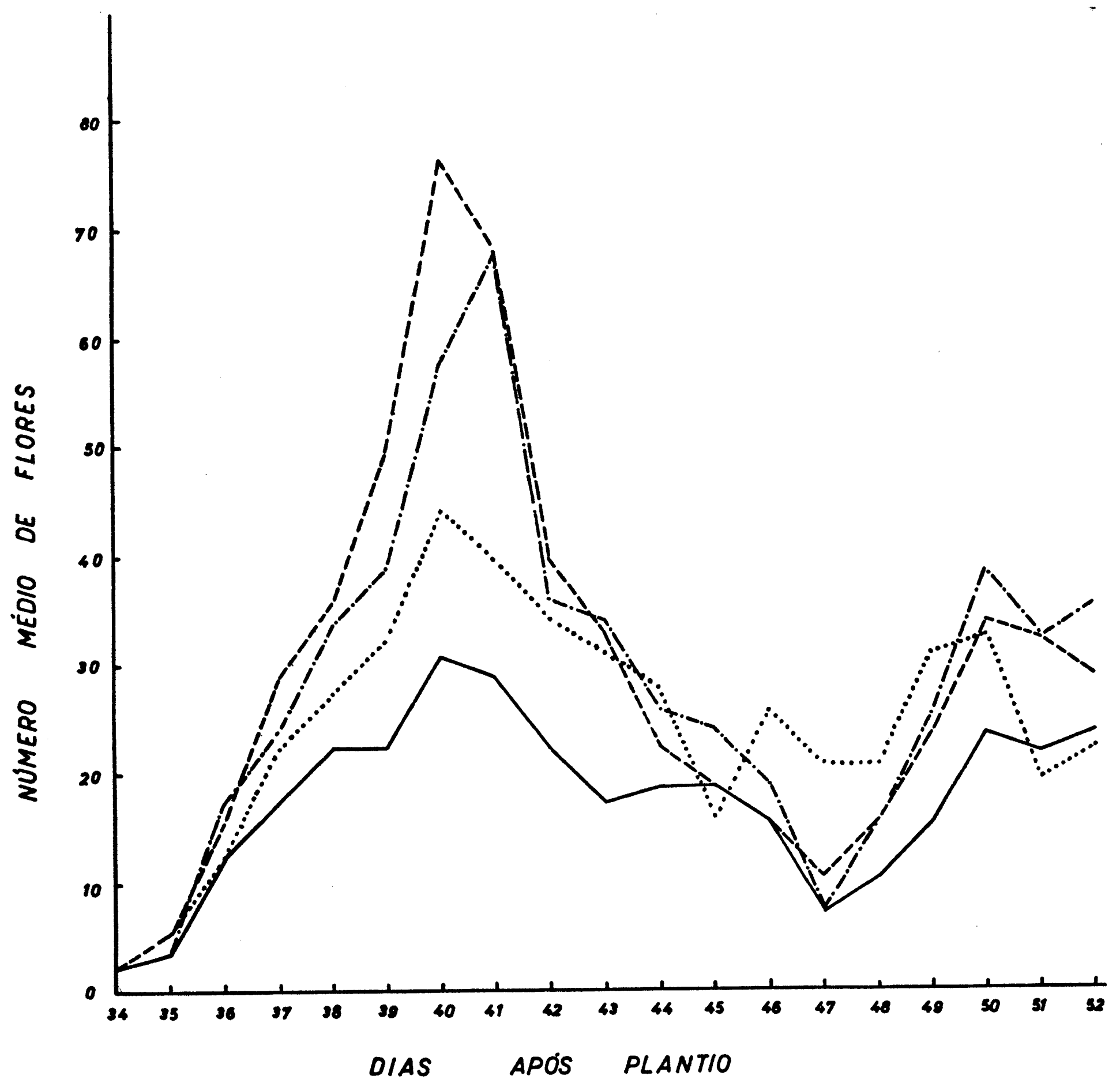


Quadro 6 - Efeitos de giberelinas no peso das vagens por planta (g), peso dos grãos por planta (g) e número de grãos por planta, sendo que o último é transformado em $\sqrt{x+0,5}$, em feijoeiro.

\begin{tabular}{l|ccc}
\hline Tratamentos & $\begin{array}{l}\text { Peso das } \\
\text { vagens/planta }\end{array}$ & $\begin{array}{l}\text { Peso dos } \text { grãos/planta } \\
\text { Testemunha }\end{array}$ & $\begin{array}{l}\text { Número de } \\
\text { grãos/planta }\end{array}$ \\
\hline $\begin{array}{l}\text { Giberelinas } \\
50 \text { ppm }\end{array}$ & 14,94 & 12,28 & 6,53 \\
\hline $\begin{array}{l}\text { Giberelinas } \\
500 \text { ppm }\end{array}$ & 21,51 & 17,27 & 7,97 \\
\hline $\begin{array}{l}\text { Giberelinas } \\
\text { 1000 ppm }\end{array}$ & 26,19 & 20,81 & 8,45 \\
\hline Média & 24,25 & 20,26 & 8,21 \\
\hline C. V.\% & 21,72 & 17,65 & 7,75 \\
\hline F & 40,68 & 41,10 & 21,76 \\
\hline
\end{tabular}

\section{CONCLUSÓES}

Os resultados obtidos neste ensaio, permitem as seguintes conclusões:

1. Os tratamentos com giberelinas a 500 e $50 \mathrm{ppm}$ revelaram uma tendência de serem mais efetivos que os tratamentos com 0 e 1000 ppm do produto, no desenvolvimento morfológico, florescimento e produtividade do feijoeiro; sendo que apenas para o comprimento do limbo foliar, o tratamento com 500 ppm do regulador de crescimento mostrou-se inferior ao controle.

2. Observou-se, no que se refere ao comprimento da haste principal, maior elongação nas plantas tratadas com giberelinas, com relação ao controle. Quanto ao comprimento dos meritalos, ocorreram diferenças significativas nos primeiros 31 dias após o plantio, sendo que após este período não houve diferenças entre os tratamentos.

3. Verificaram-se diferenças mínimas no número de meritalos e no número de folhas, nas plantas tratadas com giberelinas em relação ao controle. 
Observou-se uma ligeira superioridade na elongação dos limbos foliares, nos tratamentos com giberelinas a $50 \mathrm{ppm}$ e testemunha, com relação aos demais.

4. As aplicações de giberelinas induziram um maior florescimento ao feijoeiro; não verificou-se porém, diferenças significativas entre os tratamentos, com relação à produtividade.

\section{SUMMARY}

\section{EFFECTS OF GIBBERELLINS ON MORPHOLOGY AND PRODUCTIVITY} OF BEAN (Phaseolus vulgaris L. cv. 'Carioca').

Seedlings of (Phaseolus vulgaris L. cv 'Carioca') were treated, 7 days after germination, with gibberellins in the concentrations of 50,500 and $1000 \mathrm{ppm}$ and the check treatment, to verify the affect of the gibberellins on the morphology and productivity of the bean plant. The experiment was made under greenhouse conditions during year of 1972.

The most effective treatment with the gibberellins were obtained with the concentrations of 500 and $50 \mathrm{ppm}$ and excepting with the concentration of $500 \mathrm{ppm}$ in which one a negative result was related with the length of leaves.

There was an affective increase of elongation in the stem of the plants treated with the gibberellins. Significant differences related to the length of the internodes occurred during the first thirty-one days of growth and no significant differences were obtained after that period in the plants with gibberellins.

It was also verified in all treated plants there was a little increase in the number of internodes and in the number of leaves.

According with the number of flowers it was noted there was a tendency to increase the number of them at the concentrations of 500 and $50 \mathrm{ppm}$ of gibberellins, however the production of the beans was not significant.

\section{LITERATURA CITADA}

ALVIM, P. T. 1960 - Net assimilation rate and growth behaviour of beans as affected by gibberellic acid, urea and sugar sprays. Plant. Physiol. 35 (3) : 285-288.

CHIN, T. Y. \& J. A. LOcKHART 1965 - Translocation of applied gibberellin in bean seedlings. Amer. J. Bot. 52 (8) : 828-833.

CROSS, B. E. 1954 - Gibberellic acid. I. J. Chem. Soc. 4670-4676.

CROSS, B. E, J. F. GROVE, P. McCLOSKEY, J. McMILLAN, J. S. MOFFATT \& T. P. C. MULHOLLAND 1961 - The structures of the fungal gibberellins. Advan. Chem. Serv. $28: 3-17$.

GALSTON, A. W. \& P. J. DAVIES 1970 - Control Mechanisms in Plant Development. Prentice-Hall, Inc. New Jersey, U.S. A. 184 pp.

KURAISHI, S. \& T. HASHIMOTO 1957 - Promotion of leaf growth and acceleration of stem elongation by gibberellin. Bot. Mag. Tokyo 70:86-92.

KUROSAWA, E. 1926 - Experimental studies on the secretion of Fusarium heterosporum on rice plants. Trans. Nat. Hist. Soc. Formosa $16: 213-227$. 
LESHEM, Y. \& D. KOLLER 1966 - The control of flowering in the strawberry Fragaria ananassa Duch. II. The role of gibberellins. Ann. Bot. 30 (120) :587-595.

LESHEM, Y. \& S. STEINER 1968 - Effect of gibberellic acid and cold treatment on flower differentiation and stem elongation of cauliflower (Brassica oleraceae var. botrytis). Israel J. Agric. Res. 18 (3): 133-134.

MOH, C. C. \& J. J. ALAN 1967 - The response of a radiation - induced dwarf bean mutant to gibberellic acid. Turrialba 17 (2):176-178.

RUDDAT, M. 1969 - Biosynthesis and metabolism of steviol. In Biochemistry and Physiology of Plant Growth Substances. Ed. F. Wightman \& G. Setterfield. Runge Press. Otawa pp. 341-346.

SALISBURY, F. B. \& C. ROSS 1969 - Plant Physiology. Wadswort Publishing Company, Inc. California U.S.A. 747 pp.

WEST, C. A., M. OSTER, D. ROBINSON, F. LEW \& P. MURPHY 1969 - Biosynthesis of gibberellin precursors and related diterpene. In Biochemistry and siology of Plant Growth Substances. Ed. F. Wightman \& G. Setterfield. Runge Press. Otawa pp. 313-332.

WITTWER, S. H. \& M. J. BUKOVAC 1957 - Gibberellin and higher plants: X Field observations with certain vegetable crops. Mich. Agr. Expt. Sta. Quart. Bull. $40: 352-364$.

YABUTA, T. 1935 - Biochemistry of the "bakanae" fungus of rice. Agr. Hort. Tokyo $10: 17-22$. 